\title{
Metastatic ameloblastoma responding to combination chemotherapy: case report and review of the literature
}

\author{
Mounia Amzerin ${ }^{1 *}$, Zouhour Fadoukhair ${ }^{1}$, Rhizlane Belbaraka ${ }^{1}$, Meryem Iraqui ${ }^{2}$, Saber Boutayeb ${ }^{1}$, Hind M'rabti ${ }^{1}$, \\ Tayeb Kebdani ${ }^{2}$, Khaled Hassouni ${ }^{2}$, Najib Benjaafar ${ }^{2}$, Brahim K El Gueddari ${ }^{2}$ and Hassan Errihani ${ }^{1}$
}

\begin{abstract}
Background: Ameloblastoma is a rare benign odontogenic tumor with locally aggressive behavior and a high recurrence rate. When metastases occur, which are uncommon, lungs constitute the most frequent site involved. Malignant ameloblastomas are different from ameloblastic carcinomas. Malignant ameloblastomas are tumors considered metastatic despite the appearance of well-differentiated or benign histology, while ameloblastic carcinomas are histologically malignant in both primary and metastatic sites.

Case presentation: A 24-year-old Moroccan man presented a malignant ameloblastoma of the mandible. The tumor was entirely resected. Five years later, a local recurrence occurred. Our patient was treated by exclusive radiotherapy with persistence of a residual disease. After two years he developed multiple lung metastases. Our patient received a combination chemotherapy using doxorubicin and cisplatin.

Conclusion: Less than 50 cases of ameloblastoma with metastases have been reported. There is still no standard treatment for metastatic ameloblastoma. Only through continuous reporting of such cases will clinicians be able to draw an optimal strategy for management of this pathology.
\end{abstract}

\section{Introduction}

Ameloblastoma, from the English word "amel" which means enamel and the Greek word "blastos" which means germ [1], is a rare entity of benign odontogenic tumor. It arises from the epithelium of the dental lamina and it is known by its local aggressive behavior and the high recurrence rate [2].

Ameloblastoma was first described in 1827 by Cusack [3]. In 1885, Malassez introduced the name "adamantinoma", which is now used to describe a rare form of bone cancer described by Fisher in 1913 [4]. It was renamed to its current denomination by Churchill in 1930 [5].

In the recent WHO classification, a distinction was made between ameloblastoma, malignant ameloblastoma and ameloblastic carcinoma [2]. Malignant ameloblastoma differs from ameloblastoma due to the presence of metastases. They both have the same benign histology [6].

\footnotetext{
* Correspondence: mounia.amzerin@gmail.com

${ }^{1}$ Department of Medical Oncology, National Institute of Oncology, Rabat, Morocco

Full list of author information is available at the end of the article
}

Ameloblastic carcinoma has malignant cytologic features regardless of the presence of metastases. In ameloblastoma, metastases are uncommon. When they occur, lungs are involved in over $80 \%$ of cases [7].

Localized disease is treated by radical surgery. However, in metastatic settings, chemotherapy remains the only choice of treatment. Unfortunately, results are unpredictable. We report below a case of an ameloblastoma with metastatic evolution five years after initial surgical treatment.

\section{Case report}

A 24-year-old Moroccan man presented in 2000 with a mass of the right mandible. A panoramic radiograph revealed a multilocular radiolucency, requiring a biopsy. A histopathological examination of the specimen showed a well-differentiated neoplastic proliferation. This appeared as strands of peripheral columnar cells in palisading orientation. The fibroblastic tumor-associated stroma was dense with collagen fibers and highly infiltrated by inflammatory mononuclear cells. No histological signs of malignancy

\section{Biomed Central}


were observed (Figure 1). The diagnosis of ameloblastoma was confirmed. Treatment consisted of hemimandibulectomy. Surgical margins were free of tumor. Five years later, the lesion recurred as a mass of his right jaw. The recurrence was confirmed by a second biopsy. At the same time, a chest tomography revealed three metastatic nodules of lungs. Our patient received exclusive radiotherapy for the jaw mass, at the dose of 60 Gy. No treatment was delivered for the lung metastases. The disease was controlled for two years, until our patient presented again with a right submandibular mass and multiple bilateral lung metastases (Figure 2A). Our patient received combination chemotherapy using doxorubicin $50 \mathrm{mg} / \mathrm{m}^{2}$ and cisplatin $100 \mathrm{mg} / \mathrm{m}^{2}$. The assessment of response to chemotherapy was made after two cycles. The pain disappeared, and tomography showed, according to RECIST criteria, local stabilization and partial response of the lung lesions (30\%) (Figure 2B). The response was maintained after six cycles of chemotherapy.

\section{Discussion}

Odontogenic neoplasms are rare tumors of the oral cavity. Among these, ameloblastoma is the second most common entity after odontoma [2]. Ameloblastoma and metastatic ameloblastoma are different. According to the recent WHO classification, ameloblastoma is a localized benign disease whereas malignant ameloblastoma is considered metastatic despite the appearance of well differentiated or benign histology. Ameloblastic carcinoma shows malignant features in both primary and metastatic sites [6].

The average age at diagnosis of patients with ameloblastoma is 34 years with a range of five to 74 years [8]. Men and women are equally affected. The most frequent primary site is the angle of the mandible.

There are several histological subtypes, including plexiform, follicular, acanthomatous, basaloid, granular cell, cystic and desmoplastic forms. So far, the natural course of the disease can not be predicted. The follicular entity is the most common [2]. Basic symptoms are a swelling mass, pain and fistula in the palate [9].

Ameloblastoma is described as a slowly growing, locally invasive benign tumor with a high propensity for local recurrence. There is a $50 \%$ to $72 \%$ incidence of local recurrence after initial therapy [7]. Radical surgery remains the mainstay of therapy. This is often difficult

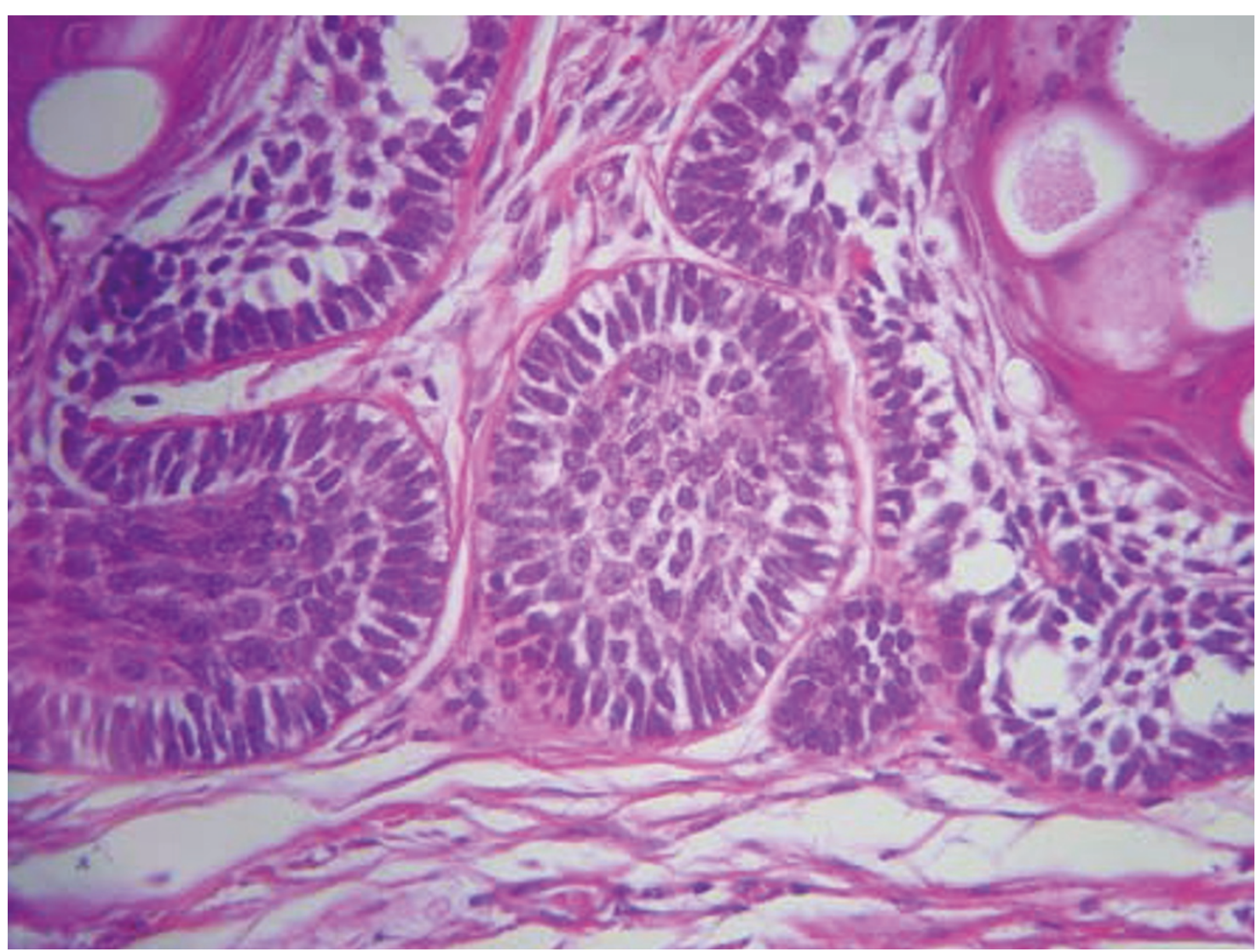

Figure 1 Histopathologic features of ameloblastoma. 

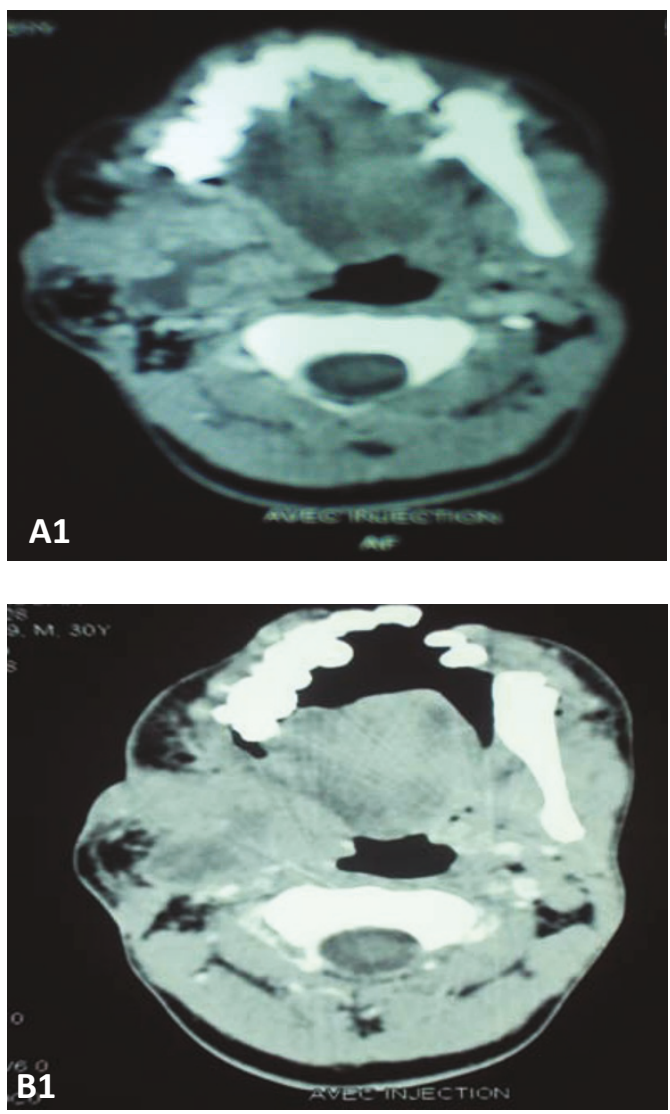
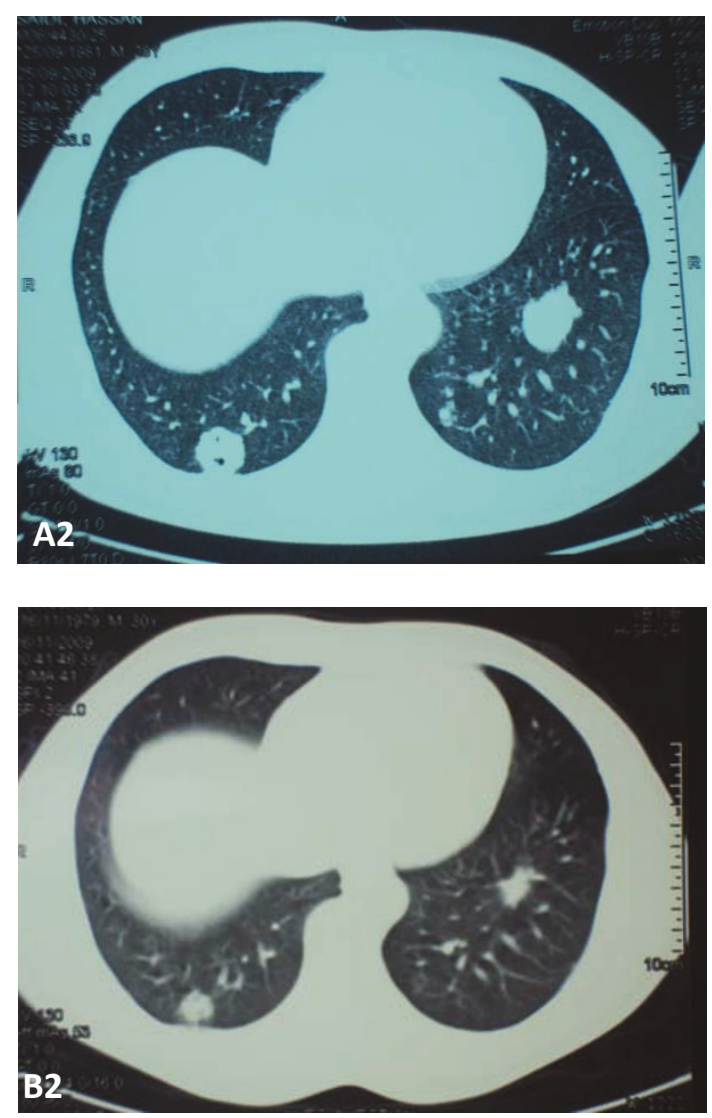

Figure 2 Presenting symptoms two years after radiothereapy. (A) Before chemotherapy 1 - right submandibular mass with endocranial extension, sphenoidal lysis and infiltration of the hemitongue; 2 - multiple lung metastases. (B) After two cycles of chemotherapy. 1 - local stabilization; 2 - partial response.

because of the anatomical complexity of the mandibular region. In case of incomplete resection, radiotherapy can be considered as an adjuvant measure.

Metastases are uncommon, which is why metastatic ameloblastoma is considered benign (in addition to the benign features on histology). They generally occur after an interval ranging from 10 to 12 years [8]. Lungs are involved in $75 \%$ to $80 \%$ of cases. Other sites may also be involved, such as regional lymph nodes, pleura, vertebra, skull, diaphragm, liver and parotid glands [6]. Many factors have been associated with the tendency to develop metastases, including extent of initial disease, multiple surgeries or radiation therapy [6-8]. Several theories have been suggested to explain metastatic spread, relating to lymphatic or hematogenous causes, aspiration or heterotopia [10].

The treatment for metastatic ameloblastoma remains delusive. When metastases are removable, surgery is the treatment of choice. Results of radiotherapy and/or chemotherapy are unpredictable and the data are poor. Less than 50 cases were reported and conclusions are disparate (Table 1). Gall tested cyclophosphamide and methotrexate 5-fluorouracil therapy in a patient with lung metastases that occurred nine years after initial therapy. He noticed that the functional outcome was good although no objective response was seen [11]. Ramadas obtained partial response after 13 cycles of combination chemotherapy-associating cisplatin and cyclophosphamide administrated for lung metastases [12]. Some other therapies have also shown activity, including vinblastine, bleomycin, paclitaxel and carboplatin [9-13].

A review of the literature made by Lanham concluded that chemotherapy failed to show any antitumoral activity, including doxorubicin, methotrexate, prednisolone, bleomycin, 5-fluorouracil and dacarbazin [14]. Moreover, the literature reports some patients with metastases showing long survival without receiving chemotherapy $[6,15]$.

Our case illustrates the natural course of the disease. In spite of radical surgery, lesions recurred. The metastases were asymptomatic. They were discovered during a classical work-up. Our finding, concerning response to doxorubicin-cisplatin, is adding to the published evidence that platinum chemotherapy is active in metastatic 
Table 1 Published data concerning chemotherapy regimens used in metastatic ameloblastoma

\begin{tabular}{|c|c|c|c|}
\hline Publication details & Regimen & Results & Reference \\
\hline CR & Cycolphosphamide & Good functional & [11] \\
\hline$-\mathrm{M}$ & Methotrexate & outcome & \\
\hline -Lung metastases & 5 Fluorouracil & OR: $0 \%$ & \\
\hline CR & Vinblastine & Partial response: $50 \%$ & [13] \\
\hline$-\mathrm{M}$ & Cisplatin & & \\
\hline -Lung metastases & Bleomycin & & \\
\hline CR & Adriamycin & Partial response & [12] \\
\hline -W, 17 years old & Cisplatin & & \\
\hline -Lung metastases & Cyclophosphamide & & \\
\hline CR & $1^{\text {st }}$ line: $5 F U$-Cisplatin & Progression disease after two cycles; repetitive partial response. & [9] \\
\hline -W, 28 years old & $2^{\text {nd }}$ line: Paclitaxel- & & \\
\hline -Lung metastases & Carboplatin & & \\
\hline CR & Cyclophosphamide & OR: $0 \%$ & [17] \\
\hline \multicolumn{4}{|l|}{$-M, 46$ years old } \\
\hline \multicolumn{4}{|l|}{-Lung metastases + mediastinal adenopathies } \\
\hline CR & No chemotherapy & Stable disease during 18 months & [6] \\
\hline \multicolumn{4}{|l|}{-M, 55 years old } \\
\hline \multicolumn{4}{|l|}{-Lung metastases } \\
\hline CR & No chemotherapy; surgery for removable metastases. & Survival: 54 years & [15] \\
\hline \multicolumn{4}{|l|}{-W, 39 years old } \\
\hline \multicolumn{4}{|l|}{-Lung metastases } \\
\hline Review & Doxorubicin \pm 5FU. & OR: $0 \%$. & [14] \\
\hline \multirow[t]{5}{*}{ Outcome of chemotherapy in metastatic ameloblastoma. } & Methotrexate \pm cyclophosphamide & & \\
\hline & Blemomycin & & \\
\hline & 5FU-Cisplatin & & \\
\hline & Vincristine & & \\
\hline & Prednisolone & & \\
\hline
\end{tabular}

CR: case report; M: man; W: woman; OR: objective response. 
ameloblastoma. Moreover, even though no objective response is seen, data show that chemotherapy improves clinical symptoms [6].

There are too few cases of metastatic ameloblastoma to consider randomized trials. Platinum-based regimens could be proposed as a first line treatment. Another pathway to explore is epidermal growth factor receptor (EGFR)-targeting. Ameloblastoma is a tumor originating from EGFR-expressing odontogenic epithelium, with expression levels ranging from $0 \%$ to $100 \%$ in some studies [16].

\section{Conclusion}

Despite the slowly growing nature of ameloblastoma, endocranial extension and/or occurrence of metastases cause pain and affect survival.

In metastatic ameloblastoma, results are unpredictable. Surgery, when feasible, remains the mainstay of therapy. There is no sufficient data to support or reject the use of chemotherapy. The expression of EGFR by odontogenic tumors could be an interesting approach to explore.

\section{Consent}

Written informed consent was obtained from our patient for publication of this case report and any accompanying images.

\section{Acknowledgements}

We are indebted to Prof Errihani, Prof Kebdani, Prof Hassouni, Prof Benjaafar, Prof Gueddari, Dr Boutayeb and Dr M'Rabti for their assistance in preparation and interpretation of the pathological findings.

\section{Author details}

'Department of Medical Oncology, National Institute of Oncology, Rabat, Morocco. ${ }^{2}$ Department of Radiotherapy, National Institute of Oncology, Rabat, Morocco.

\section{Authors' contributions}

MA performed literature review, the composition of this case report and manuscript writing.

$\mathrm{ZF}, \mathrm{RB}$ and $\mathrm{MI}$ were involved in the conception and design, collection and assembly of the data.

\section{Competing interests}

The authors declare that they have no competing interests.

Received: 11 December 2010 Accepted: 3 October 2011 Published: 3 October 2011

\section{References}

1. Brazis PW, Miller NR, Lee AG, Holliday MJ: Neuro-ophthalmologic aspects of ameloblastoma. Skull Base Surg 1995, 5(4):233-244.

2. Jordan RCK, Speight PM: Current concepts of odontogenic tumours. Diagn Histopathol 2009, 15(6):303-310.

3. Cusack JW: Report of the amputations of the lower jaw. Dublin Hosp Rec 1827, 4:1-38.

4. Malassez L: Sur Le role des debris epitheliaux papdentaires. Arch Physiol Norm Pathol 1885, 5:309-340, 6:379-449.
5. Ivery RH, Churchill L: The need of a standardized surgical and pathological classification of tumors and anomalies of dental origin. Am Assoc Dent Sch Trans 1930, 7:240-245.

6. Ciment LM, Ciment AJ: Malignant ameloblastoma metastatic to the lungs 29 years after primary resection. Chest 2002, 121:1359-1361.

7. Henderson JM, Sonnet JR, Schlesinger C, Ord RA: Pulmonary metastasis of ameloblastoma: case report and review of the literature. Oral Surg Oral Med Oral Pathol Oral Radiol Endod 1999, 88(2):170-176.

8. Gilijamse $M$, Leemans $C R$, Winters HA, Schulten EA, van der Waal I: Metastasizing ameloblastoma. Int J Oral Maxillofac Surg 2007, 36(5):462-464.

9. Grünwald V, Le Blanc S, Karstens JH, Weihkopf T, Kuske M, Ganser A, Schöffski P: Metastatic malignant ameloblastoma responding to chemotherapy with paclitaxel and carboplatin. Ann Oncol 2001 12(10):1489-1491.

10. Houston G, Davenport W, Keaton W, Harris S: Malignant ameloblastoma: report of a case. J Oral Maxillofac Surg 1993, 51:1152-1155, discussion 1156-1157.

11. Gall JA, Sartiano GP, Shreiner DP: Ameloblastoma of the mandible with pulmonary metastasis. Oncology 1975, 32(3-4):118-126.

12. Ramadas K, Jose CC, Subhashini J, Chandi SM, Viswanatham FR: Pulmonary metastases from ameloblastoma of the mandible teated with cisplatin, adriamycin and cyclophosphamid. Cancer 1989, 66:1475-1479.

13. Eliasson AH, Moser RJ, Tenholder MF: Diagnosis and treatment of metastatic ameloblastoma. South Med J 1989, 82(9):1165-1168.

14. Lanham RJ: Chemotherapy of metastatic ameloblastoma. A case report and review of the literature. Oncology 1987, 44(2):133-134.

15. Hasim FW, Poon CC, Smith A: Prolonged survival with confirmed metastatic pulmonary ameloblastoma. Int J Oral Maxillofac Surg 2007, 36(10):953-935.

16. Vered M, Shohat I, Buchner A: Epidermal growth factor receptor expression in ameloblastoma. Oral Oncol 2003, 39(2):138-143.

17. Campbell $D$, Jeffrey RR, Wallis $F$, Hulks $G$, Kerr KM: Metastatic pulmonary ameloblastoma: an unusual case. Br J Oral Maxillofac Surg 2003, 41(3):194-196.

doi:10.1186/1752-1947-5-491

Cite this article as: Amzerin et al:: Metastatic ameloblastoma responding to combination chemotherapy: case report and review of the literature. Journal of Medical Case Reports 2011 5:491.

\section{Submit your next manuscript to BioMed Central and take full advantage of:}

- Convenient online submission

- Thorough peer review

- No space constraints or color figure charges

- Immediate publication on acceptance

- Inclusion in PubMed, CAS, Scopus and Google Scholar

- Research which is freely available for redistribution

Submit your manuscript at www.biomedcentral.com/submit 